\title{
Induction of ER stress in response to oxygen-glucose deprivation of cortical cultures involves the activation of the PERK and IRE-1 pathways and of caspase-12
}

\author{
N Badiola ${ }^{1,2,3}$, C Penas ${ }^{1,4,3}$, A Miñano-Molina ${ }^{1,3}$, B Barneda-Zahonero ${ }^{1,2,3}$, R Fadót ${ }^{1,2,3}$, G Sánchez-Opazo ${ }^{1,2,3}$, JX Comella ${ }^{1,2,3}$,

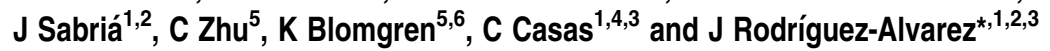

Disturbance of calcium homeostasis and accumulation of misfolded proteins in the endoplasmic reticulum (ER) are considered contributory components of cell death after ischemia. However, the signal-transducing events that are activated by ER stress after cerebral ischemia are incompletely understood. In this study, we show that caspase-12 and the PERK and IRE pathways are activated following oxygen-glucose deprivation (OGD) of mixed cortical cultures or neonatal hypoxia-ischemia (HI). Activation of PERK led to a transient phosphorylation of elF2 $\alpha$, an increase in ATF4 levels and the induction of gadd34 (a subunit of an elF2 $\alpha$ directed phosphatase). Interestingly, the upregulation of ATF4 did not lead to an increase in the levels of CHOP. Additionally, IRE1 activation was mediated by the increase in the processed form of xbp1, which would be responsible for the observed expression of edem2 and the increased levels of the chaperones GRP78 and GRP94. We were also able to detect caspase-12 proteolysis after $\mathrm{HI}$ or OGD. Processing of procaspase-12 was mediated by NMDA receptor and calpain activation. Moreover, our data suggest that caspase-12 activation is independent of the unfolded protein response activated by ER stress.

Cell Death and Disease (2011) 2, e149; doi:10.1038/cddis.2011.31; published online 28 April 2011

Subject Category: Neuroscience

Brain ischemia is caused by decreased blood supply to the brain, for example in stroke in adults or perinatal asphyxia in newborns. The deprivation of oxygen and glucose (OGD) in the ischemic brain eventually leads to cell death, which was believed to have necrotic features. Over the last decade, this view has been challenged. Mounting evidence indicates that activation of caspases occurs in the ischemic brain tissue ${ }^{1}$ or in cultured cortical neurons transiently deprived of oxygen and glucose, ${ }^{2}$ suggesting that the loss of neurons by apoptosis might be important, especially in the penumbra area. It has been shown that in OGD-treated cortical cultures, at least $50 \%$ of dying cells showed morphological characteristics of apoptosis and the activation of caspase-3, -7 and -9 in neurons and microglial cells. ${ }^{2}$

The unfolded protein response (UPR) was first identified as a cellular response signaling to preserve the organelle function once misfolded or unfolded proteins were accumulated in the ER. Later on, it was found that the ER stress and UPR activation can be also induced by various stimuli such as disruption of calcium homeostasis or inhibition of glycosylation, and it may end up with apoptosis. ${ }^{3}$ The UPR is essentially carried out by three ER-transmembrane effectors proteins: the RNA-activated protein kinase-like ER resident kinase (PERK), the inositol-requiring kinase (IRE1) and the activating transcription factor 6 (ATF6). In the physiological state, PERK, IRE1 and ATF6 activity is suppressed by binding of the ER chaperone glucose-regulated protein 78 (GRP78, also called $\mathrm{BiP}$ ) to the ER-transmembrane effectors. In response to ER stress GRP78 dissociates and binds to the unfolded proteins to facilitate refolding, this allows the activation of PERK, IRE1 and ATF6. ${ }^{4,5}$ Overall, UPR activation can help the cell to cope with the ER stress, but if it is persistent it can also contribute to cell death. ${ }^{3}$ Caspase-12 activation was also associated with the cell damage induced by ER stress; ${ }^{6,7}$ however, some reports suggest that it is not always necessary for ER stressinduced apoptosis. ${ }^{8}$

Some evidence suggesting that ER stress has an important role in cerebral ischemia has seemed during the last years. ${ }^{9}$ Activation of some ER stress-related molecules had been described in transient focal or global cerebral ischemia ${ }^{10,11}$ and in primary neuronal cultures following in vitro ischemia. ${ }^{12}$ However, it is still not well understood how ER-transmembrane effectors proteins and other molecular mechanisms are involved.

\footnotetext{
${ }^{1}$ Institut de Neurociencies and Universitat Autònoma de Barcelona, Barcelona, Spain; ${ }^{2}$ Departament de Bioquímica i Biología Molecular and Universitat Autònoma de Barcelona, Barcelona, Spain; ${ }^{3}$ Centro de Investigación Biomédica en Red sobre Enfermedades Neurodegenerativas (CIBERNED), Barcelona, Spain; ${ }^{4}$ Departament de Biología Celular, Fisiologia e Inmunologia, Universitat Autònoma de Barcelona, Barcelona, Spain; ${ }^{5}$ Center for Brain Repair and Rehabilitation, Institute of Neuroscience and Physiology, University of Gothenburg, Gothenburg, Sweden and ${ }^{6}$ Department of Pediatric Oncology, The Queen Silvia Children's Hospital, Gothenburg, Sweden ${ }^{*}$ Corresponding author: J Rodriguez-Alvarez, Institut de Neurociències, Edificio M, Campus de Bellaterra, Universitat Autònoma de Barcelona, Cerdanyola del Vallès, Barcelona 08193, Spain. Tel: + 3493581 1525; Fax: + 3493581 1573; E-mail: jose.rodriguez@uab.es

Keywords: endoplasmic reticulum stress; apoptosis; caspase-12; ischemia; cell culture; brain

Abbreviations: ALLN, calpain inhibitor I; ATF6, activating transcription factor 6; BfA, brefeldin A; DTT, dithiothreitol; elF2 $\alpha$, eukaryotic initiation factor $2 \alpha$; ER, endoplasmic reticulum; ERAD, endoplasmic reticulum-associated degradation; ERSE, endoplasmic reticulum stress response element; GRP, glucose-regulated protein; HI, hypoxia-ischemia; IRE-1, inositol-requiring kinase; NMDA, N-methyl-D-aspartate; MTT, 3-(4,5-dimethylthiazol-2-yl)-2, 5-diphenyl tetrazolium bromide; OGD, oxygenglucose deprivation; PERK, RNA-activated protein kinase-like ER resident kinase; RT-PCR, reverse-transcription PCR; SDS, sodium dodecyl sulfate; Tg, thapsigargin; UPR, unfolded protein response

Received 08.10.10; revised 04.3.11; accepted 10.3.11; Edited by A Verkhrasky
} 
In this study, we show for the first time that the PERK and IRE pathways are activated following neonatal hypoxiaischemia (HI). Furthermore, we have used an OGD paradigm in mixed cortical cell cultures to study in more detail the ER stress-related pathways involved in ischemic damage. Our results show that OGD induced ER stress by activating PERK and IRE1 pathways and that OGD-mediated activation of caspase-12 is dependent of NMDA receptor-mediated calpain activation.

\section{Results}

PERK-elF2 $\alpha$ pathway is activated in OGD. In previous studies, we have reported that apoptosis was contributing to neuronal death observed after neonatal $\mathrm{HI}^{13}$ and OGD in mixed cortical cultures, ${ }^{2}$ where we have also confirmed that ER stress is elicited with thapsigargin (Tg) or Blefeldin A (see Supplementary Figures 1 and 2).

To dissect the molecular pathways involved in ER stress, we first studied the activation of the PERK-mediated pathway. As described in Figure 1a, PERK was phosphorylated at $15 \mathrm{~min}$ post-OGD, and elF2 $\alpha$ was heavily phosphorylated during the first $30 \mathrm{~min}$ after OGD. elF2 $\alpha$ phosphorylation was already evident after the OGD period, with a maximum by $15 \mathrm{~min}$ later and returned to basal levels $1 \mathrm{~h}$ after the end of OGD. Although phosphorylation of elF2 $\alpha$ causes a global inhibition of protein synthesis, it increases the translation of rare mRNAs containing upstream open reading frames, such as ATF4. ${ }^{14}$ We found that ATF4 protein levels rose soon after the OGD period and they returned to normal levels at $6 \mathrm{~h}$ (Figure 1b). The dephosphorylation of elF2 $\alpha$ brought us to analyze the levels of gadd34. Gadd34 encodes a regulatory subunit of an elF $2 \alpha$-directed phosphatase complex that serves as a regulatory loop to mitigate the activation of PERK. ${ }^{15}$ As expected gadd34 expression was upregulated after OGD (Figure 1c) and was followed by an increase in protein levels (Figure 1d). Altogether, these data suggest that PERK-elF2 $\alpha$ pathway is activated by OGD.

OGD activates IRE1-XBP1 pathway and the upregulation of GRP78 and GRP94. We observed an upregulation of grp78 and grp94 transcripts at 6 and $12 \mathrm{~h}$ after OGD (Figure 2a). The increase in the expression of both chaperones was accompanied by a significant increase in their protein levels after OGD. Protein levels peaked at 12 and $24 \mathrm{~h}$ and declined to basal values at $48 \mathrm{~h}$ (Figure $2 \mathrm{~b}$ ). To identify transcription factors responsible for the increase in GRP78 and GRP94, we decided to monitor the involvement of ATF6 and/or XBP1 that are able to bind to the endoplasmic reticulum stress response element (ERSE) present in the chaperones promoters.

Under ER stress, full-length ATF6 $(90 \mathrm{kDa})$ is cleaved in the Golgi apparatus by SP1 and SP2 proteases to yield a cytosolic fragment $(50 \mathrm{kDa})$ that migrates to nucleus to activate transcription of genes containing ERSE sequence on their promoters. Recently, the presence of an underglycosilated form of ATF6 was described as a novel sensing mechanism for the activation of the UPR. ${ }^{16}$ We found a decrease in full-length ATF6 $(90 \mathrm{kDa})$ and the appearance of a faster a

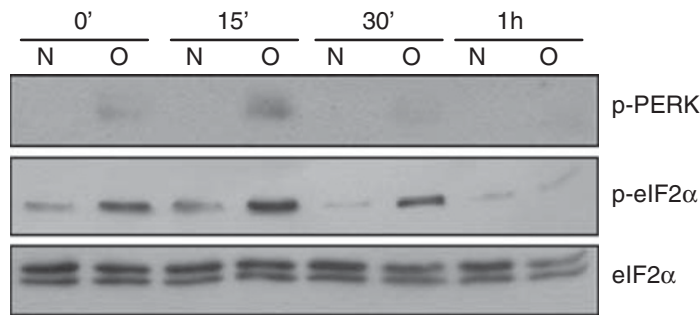

b

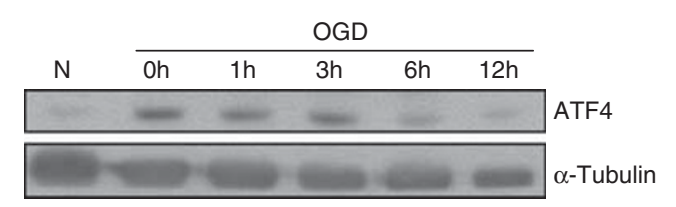

C
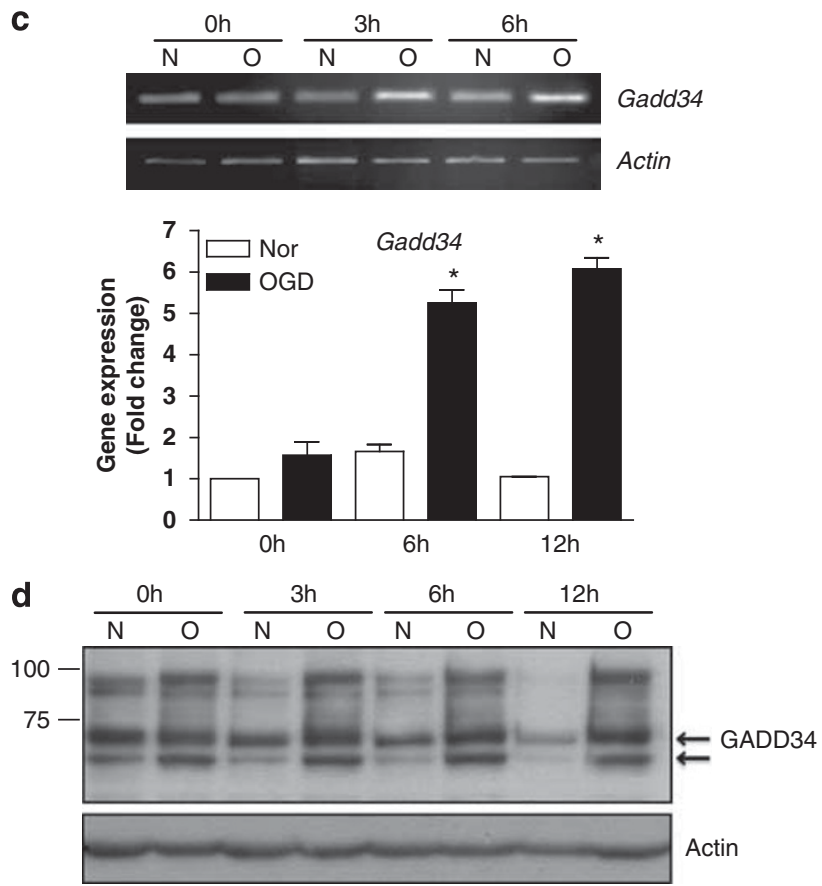

Figure 1 OGD activates PERK-elF2 $\alpha$ pathway. (a) Western blot analysis of total eiF2 $\alpha$ and phosphorylated elF2 $\alpha$ (p-elF2 $\alpha$ ) and PERK after OGD. (b) Western blot analysis of ATF4 levels at indicated times after OGD. $\alpha$-tubulin was used as loading control. (c) RT-PCR products for gadd34 obtained from cortical cultures at indicated times after OGD (top). Histogram quantification of the fold change in gadd34 expression respect to actin levels (bottom). ${ }^{*} P<0.001$ versus control. (d) Western blot analysis of GADD34 levels at indicated times in normoxia (N) and after OGD (O). Actin was used as loading control

migrating band (f) $24 \mathrm{~h}$ after OGD (Figure 2c). This band appeared also when cells were treated with $\mathrm{Tg}$, in accordance with previous observations. ${ }^{17}$ However, the observed activation of ATF6 $24 \mathrm{~h}$ after OGD could not be responsible for the early increase in the expression of grp78 and grp94. Thereafter, we decided to study whether the IRE pathway could be responsible for the increased levels of the chaperones. When IRE1 is activated by ER stress, it functions as an mRNA endonuclease and process the mRNA of $x b p 1$ leading to its efficient translation into an ERSE-binding transcription factor. ${ }^{18}$ We found an increase of spliced $x b p 1$ after OGD, but also after normoxia (control conditions; Figure 2d). Although the increase during OGD and normoxia was similar at $6 \mathrm{~h}$, the 


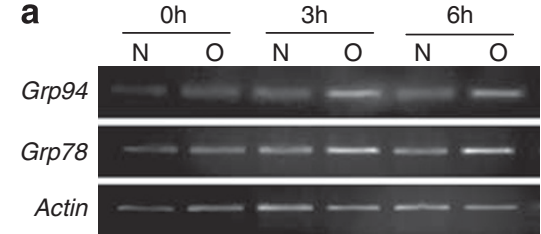

b $\frac{6 \mathrm{~h}}{\mathrm{~N} O} \frac{12 \mathrm{~h}}{\mathrm{~N} O} \frac{24 \mathrm{~h}}{\mathrm{~N} O} \frac{48 \mathrm{~h}}{\mathrm{~N} O}$
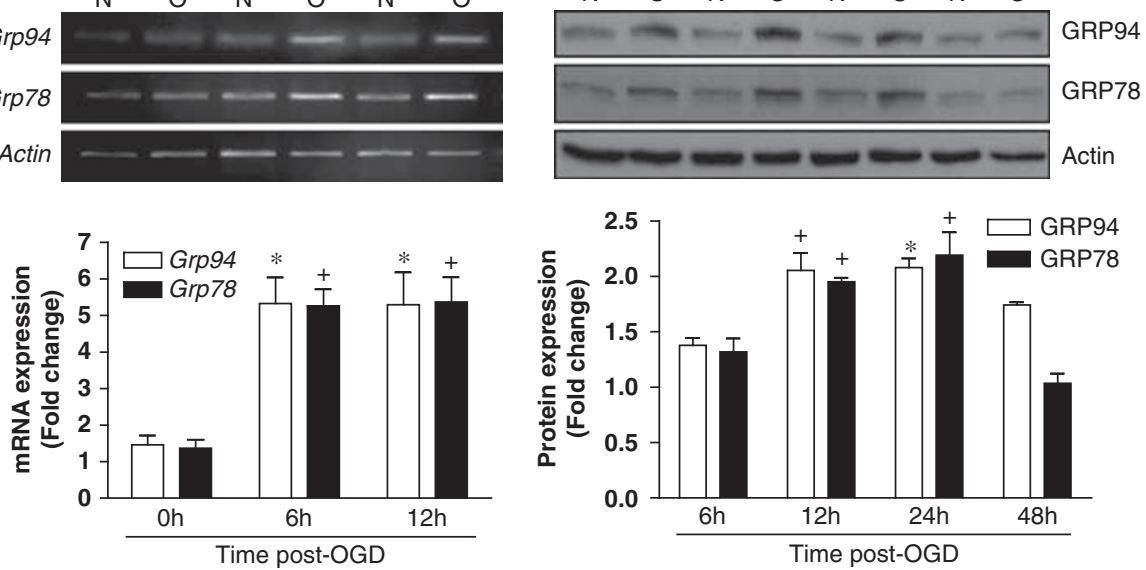

C

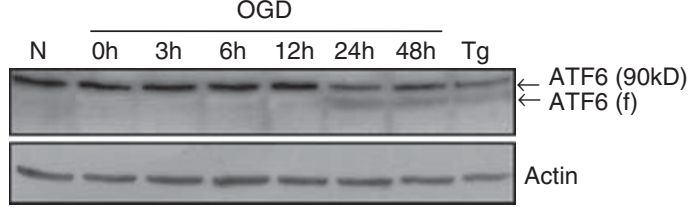

d
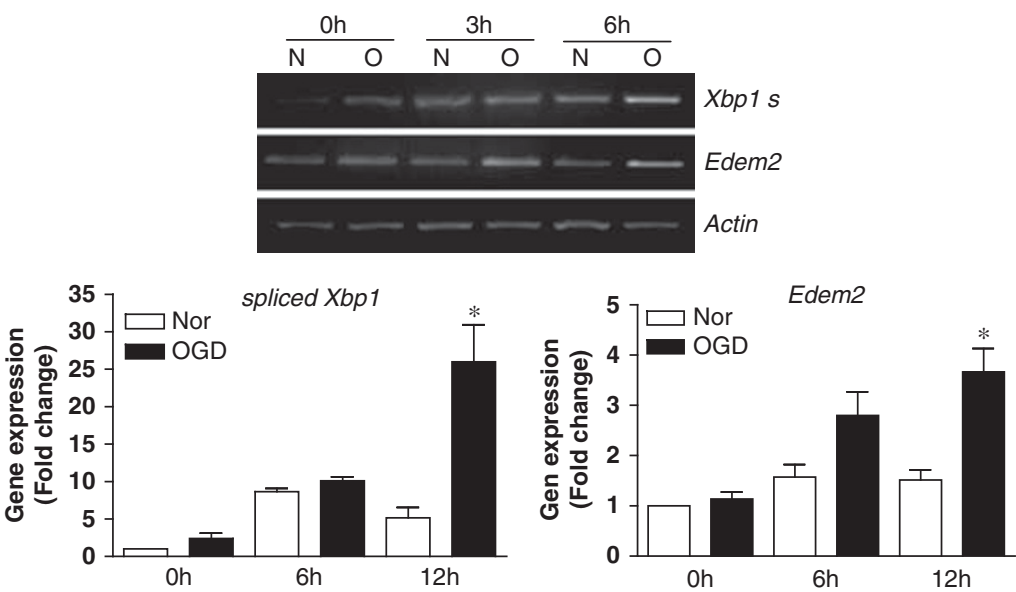

Figure 2 OGD activates IRE1-XBP1 pathway. (a) RT-PCR products for grp78 and grp94 obtained from cortical cultures at indicated times after OGD (top). Quantification of grp78 and grp94 mRNAs, normalized to actin levels (bottom). ${ }^{\star} P<0.01$ and ${ }^{+} P<0.001$ versus control. (b) Time course of GRP78 and GRP94 protein expression in cortical cultures exposed to OGD. Membranes were also immunoblotted with an anti-actin antibody as loading control (top). Quantification of protein levels of GRP78 and GRP94 normalized to actin levels (bottom). ${ }^{*} P<0.05$ and ${ }^{+} P<0.001$ versus control. (c) ATF6 protein expression was study by western blot at different times after OGD. ATF6 (f) is ATF6 form that migrates faster. A lysate of Tg-treated cells $(5 \mu \mathrm{M})$ was loaded as a positive control. (d) RT-PCR products for $x b p 1$ and edem2 obtained from cortical cultures at indicated times after OGD (top). The processed $x b p 1$ was obtained as explained in materials and methods section. Quantification of spliced $x b p 1$ and edem2 mRNAs, normalized to actin levels (bottom). ${ }^{*} P<0.001$ versus control

level of spliced xbp1 was significantly higher in OGD versus normoxia at $12 \mathrm{~h}$. The increase of processed $x b p 1$ observed under normoxia was related to an increase in the transcription activity of XBP1, as the expression of edem2 (ER degradation-enhancer, mannosidase alpha-like protein 2), a target gene of XBP, was significantly increased after OGD but not under normoxic conditions (Figure 2d).

OGD-mediated caspase-12 activation is calpain and NMDA receptor dependent. Caspase-12 is an ERresident pro-caspase that is proteolyzed in response to ER stress conditions ${ }^{19}$ releasing two catalytic subunits, p20 and p10. Treatment of our cultures with $\mathrm{Tg}$, a well-known ER stress inducer, produced a decrease in the pro-caspase-12 levels and the appearance of the p20 subunit (Figure $3 a$ and Supplementary Figure 1B). When the cultures were deprived of oxygen and glucose, a clear reduction in procaspase-12 was observed after $6 \mathrm{~h}$ until $48 \mathrm{~h}$, whereas p20 was only detected after 12 and $24 \mathrm{~h}$ (Figure 3a). We were able to observe the presence of other fragments produced by procaspase-12 proteolysis $48 \mathrm{~h}$ after OGD or in Tg-treated cultures (Figure 3a). It is known that caspases proteolysis does not always trigger their activation. Thus, we determined caspase-12 activity by a fluorimetric assay. As it is shown in Figure 3c, OGD produced a significant increase $(60 \%)$ in caspase-12 activity versus normoxia. It is described that 


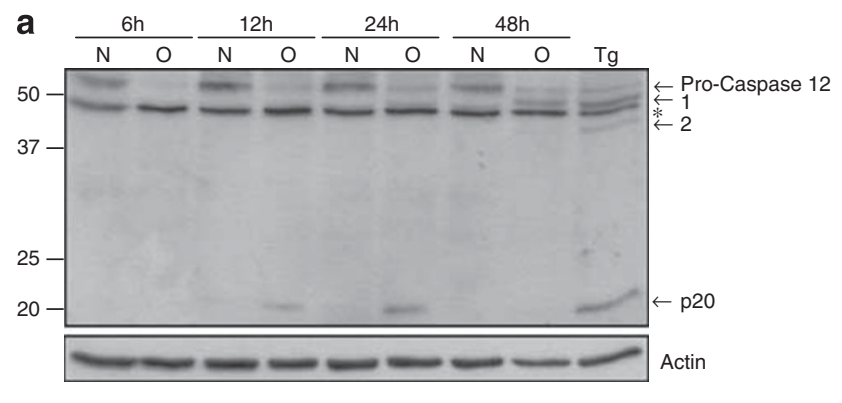

b $\frac{N 3 h}{+Z . V A D} \frac{O 3 h}{+Z . V A D} \frac{O 6 h}{+Z . V A D} \frac{O 12 h}{+Z . V A D}$
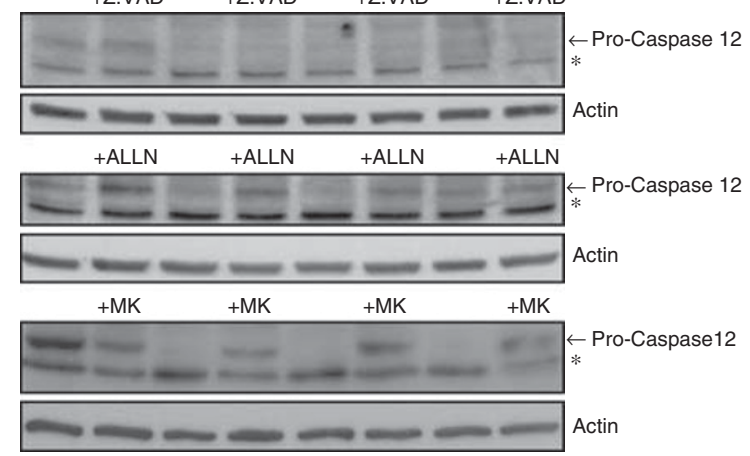

C

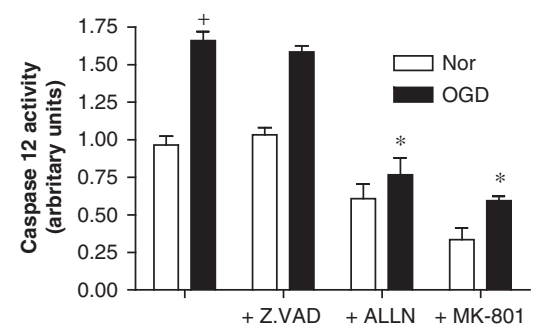

d

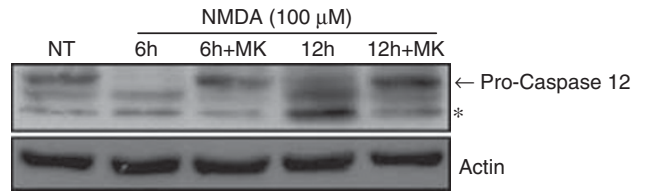

Figure 3 OGD-mediated activation of caspase-12 is calpain dependent. (a) Western blot analysis of caspase-12 at indicated times in cultures exposed to OGD. A lysate of Tg-treated cells $(5 \mu \mathrm{M})$ was loaded as a positive control of caspase-12 activation. Arrows indicate pro-caspase-12 cleavage products. Asterisk indicates a nonspecific band. (b) Procaspase-12 proteolysis analysis by western blot in cultures exposed to normoxia $(\mathrm{N})$ or OGD $(\mathrm{O})$ in presence of caspase paninhibitor, z-VAD-fmk $(100 \mu \mathrm{M})$, calpain inhibitor, ALLN $(1 \mu \mathrm{M})$ or NMDA receptor agonist, MK-801 $(10 \mu \mathrm{M})$. (c) Caspase-12 activity was determined at $6 \mathrm{~h}$ by a fluorimetric assay as described in materials and methods section. Histograms represent the activity in normoxia (Nor) or after OGD in cultures treated with the indicated inhibitors. Activity observed in normoxia control cultures (normoxia without inhibitors) was taken as reference and considered to be 1 . Results are mean \pm S.E.M. of three independent experiments performed in triplicate. ${ }^{+} P<0.01$ versus normoxia and ${ }^{*} P<0.01$ versus OGD (d) Procaspase-12 proteolysis in cortical cultures treated for 6 or $12 \mathrm{~h}$ with NMDA $(100 \mu \mathrm{M})$ in the presence or absence of MK-801. All the membranes were also immunoblotted with an anti-actin antibody as a loading control

caspase- 12 activation can be mediated by caspase- $7^{20}$ or by homodimerization of procaspase-12. ${ }^{21}$ Thus, we decided to treat the cultures with the caspase pan-inhibitor zVAD in order to know whether caspase activity was mediating the processing of procaspase-12 in OGD cultures. As shown in Figures $3 b$ and $c$, the presence of $z V A D$ in the culture media was not able to block neither OGD-mediated procaspase-12 proteolysis nor its activation. In contrast, the presence of calpain inhibitors, such as ALLN or MDL 28170, completely blocked the proteolysis of procaspase-12 (Figure $3 \mathrm{~b}$ and data not shown) and OGD-mediated caspase-12 activation (Figure 3c), suggesting that calpains are responsible for the OGD-mediated activation of caspase-12. Calpains are calcium-dependent proteases and it is well know that the NMDA receptor, a major entry route for this divalent cation, is activated by OGD. Accordingly, the use of MK-801, an irreversible NMDA receptor antagonist, in OGD cultures was able to completely block procaspase-12 proteolysis and activation (Figures $3 \mathrm{~b}$ and $\mathrm{c}$ ). Thus, our data support that NMDA receptor-mediated influx of calcium in OGD cultures is responsible for calpain-mediated procaspase-12 proteolysis activation. Accordingly, treatment of the cultures with NMDA produced proteolysis of procaspase-12 (Figure 3d).

ER stress is induced in neonatal cerebral HI. Brain injury after neonatal cerebral $\mathrm{HI}$ includes focal ischemic infarction and cell loss with apoptotic features such as caspase activation and DNA fragmentation. ${ }^{22}$ However, it is not known whether ER stress is induced after neonatal cerebral HI. To assess whether ER stress is induced after $\mathrm{HI}$, we determined the activation of the UPR by analyzing the phosphorylation of elF $2 \alpha($ elF $2 \alpha-\mathrm{P})$, the protein levels of the chaperones GRP78 and GRP94 and the eventual activation of caspase-12.

Direct phosphorylation of elF $2 \alpha$ by PERK leads to general protein synthesis shut off to prevent ER overload. ${ }^{23}$ As shown in Figure 4a, we observed an increase in elF2 $\alpha-P$ in the ipsilateral compared with the contralateral hemisphere inmediately after $\mathrm{HI}$, although $3 \mathrm{~h}$ later, phosphorylation in the ipsilateral hemisphere returned to basal levels, indicating that the phosphorylation of this factor is acute and transient. A progressive increase in the protein levels of chaperones GRP78 and GRP94 was also observed after $\mathrm{HI}$ in the ipsilateral hemisphere (Figure 4b). On the other hand, we also observed that $\mathrm{HI}$ induced proteolysis of procaspase-12 in the ipsilateral hemisphere (Figure 4c). Altogether, these results confirm that $E R$ stress is induced in neonatal cerebral $\mathrm{HI}$.

\section{Discussion}

The ER has an important role in the maintenance of intracellular calcium homeostasis, the post-translational modifications and proper folding of proteins synthesized in the ribosomes. Some evidence suggests that the energy depletion and disruption of calcium homeostasis that occurs during an ischemic process could trigger the accumulation of misfolded proteins in the ER lumen and activation of the UPR. ${ }^{24,25}$ It has been widely reported that the UPR is launched by the activation of the ER-transmembrane effectors proteins, PERK, IRE1 or ATF6. However, it is not well established which effectors are activated in the cerebral ischemia-mediated UPR. Some reports have described the activation of PERK after transient forebrain ischemia, but although the increase in phosphorylation of elF $2 \alpha$ and in ATF4 expression is not challenged, ${ }^{26}$ the activation of $\mathrm{CHOP}$ is 

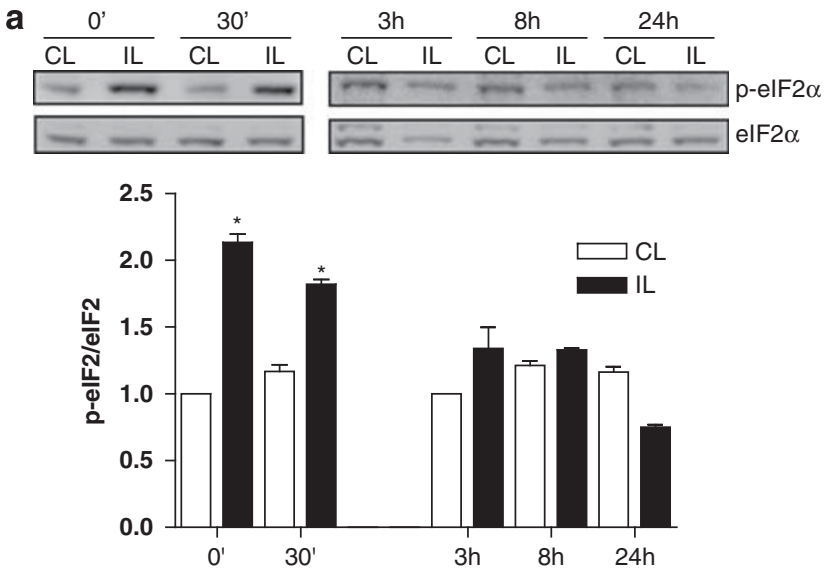

b
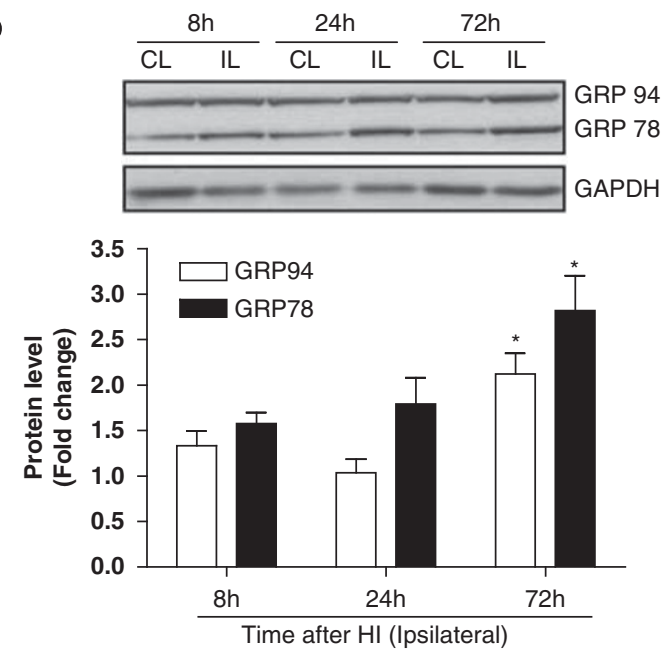

C

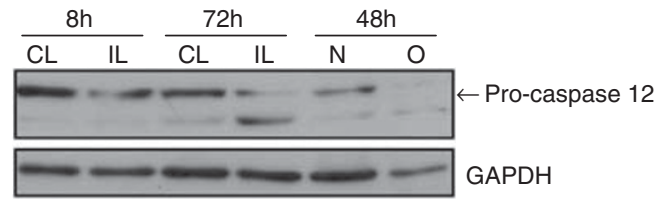

Figure $4 \mathrm{HI}$ induces ER stress. (a) Western blot analysis of total eiF2 $\alpha$ and phosphorylated elF2 $\alpha$ (p-elF2 $\alpha$ ) at different times after HI. Pooled samples of homogenates from contralateral $(\mathrm{CL})$ or ipsilateral (IL) cortex were loaded. Quantification of the $\mathrm{p}$-eiF2 versus elF2 ratio (bottom). ${ }^{*} P<0.05$ versus $\mathrm{CL}$. (b) Western blot analysis of GRP78 and GRP94 protein expression after HI (left). Histogram quantification of pooled samples normalized with respect to GAPDH levels and showed as fold change versus $\mathrm{CL}$ at $0 \mathrm{~h}\left({ }^{*} P<0.05\right)$. (c) Pro-caspase-12 proteolysis analysis by western blot, in cortex homogenates of animals exposed to $\mathrm{HI}$. Lysates of cortical neurons culture exposed to $\mathrm{OGD}(\mathrm{O})$ and control $(\mathrm{C})$ were use to confirm the proteolysis of procaspase-12. GAPDH was used as loading control

controversial. ${ }^{10,27}$ Few studies have addressed the role of IRE 1 and ATF6 effectors. Paschen et al. ${ }^{28}$ described a marked increase in processed $x b p 1 \mathrm{mRNA}$, indicating that IRE 1 should be activated in transient focal cerebral ischemia. However, the processing of $x b p 1$ mRNA was not observed in another study after transient global cerebral ischemia. ${ }^{27}$

Neonatal $\mathrm{HI}$ is a major cause of neurological deficits and shares similar molecular injury mechanisms with stroke in adult brains. However, it is not known whether ER stress is induced after neonatal HI. Here, we have shown a fast increase in p-elF2 $\alpha$, which is followed by upregulation of the chaperones GRP78 and GRP94 and pro-caspase-12 proteolysis. To explore in more detail the molecular mechanisms involved, we took advantage of an in vitro model where mixed neuronal-glial cortical cultures were obtained from embryonic rats and deprived of oxygen and glucose. Our results suggest the activation of PERK and IRE1 early after OGD.

In accordance with the data observed after neonatal $\mathrm{HI}$, a rapid phosphorylation of PERK and elF2 $\alpha$ was observed at 30 min after OGD in mixed cortical cultures, suggesting that protein synthesis inhibition, induced by PERK activation, occurs just after injury and is transient. A similar, fast and transient phosphorylation of elF2 $\alpha$ was described in other models of ischemia, such as the middle cerebral artery occlusion (MCAO) and the four-vessel occlusion (4VO). ${ }^{24,27}$ It is well known that protein synthesis inhibition induced by phosphorylation of elF2 $\alpha$ could be bypassed for some rare mRNAs including ATF4 mRNA. ${ }^{14}$ We found increased levels of ATF4 until $3 \mathrm{~h}$ after OGD. Similar results were observed previously after global cerebral ischemia ${ }^{11}$ or permanent middle cerebral artery occlusion. ${ }^{11,29}$ However, failure to detect an increase in ATF4 has been also reported. ${ }^{27}$ The observed increase in ATF4 levels after OGD was further confirmed, as we have detected OGD-mediated expression of gadd34, a protein phosphatase-1 subunit that dephosphorylates $\mathrm{p}$-elF2 $\alpha$ and is upregulated by ATF4. ${ }^{30}$ Interestingly, the increase in gadd34 expression was observed when ATF4 has returned to basal levels. However, the negative feed-back control of translation arrest due to Gadd34-mediated dephosporylation of p-elF $2 \alpha$ could be avoided by the action of other factors besides elF $2 \alpha$ such as elF24 family-like proteins that exert an effect at different level in ribosomal recruitment. ${ }^{31,32}$

IRE1 is an mRNA endoribonuclease, which under ER stress is activated and cleaves a $26 \mathrm{nt}$ 'non-classical intron' from $x b p 1 \mathrm{mRNA}$ in a reaction homologous to tRNA transcript processing. ${ }^{33}$ The processing of $x b p 1$ mRNA promotes efficient translation of XBP1 into an ERSE-binding transcription factor with overlapping specificity to ATF6. ${ }^{18}$ Our results show that OGD activates IRE1, as we were able to detect an increase in the processed $x b p 1$. Thus, our results are in agreement with a previous study that reported the processing of $x b p 1$ after transient global or focal cerebral ischemia. ${ }^{28}$ XBP1 functions as a transcription factor for ER-stress genes such as edem2. EDEM2 is required for efficient degradation of glycoproteins misfolded in the ER in the process called ERassociated degradation (ERAD). ${ }^{34}$ The fact that OGD upregulated edem2, confirms that IRE1 was activated and also suggests that ERAD is involved in the degradation of misfolded proteins.

One of the hallmarks of ER stress is the induction of the chaperones GRP78 and GRP94. This induction, which is a part of the UPR, is required to decrease ER stress and facilitate protein folding. Some studies have shown the induction of these chaperones after cerebral brain ischemia. ${ }^{7}$ Recently, similar results have been described after OGD in cortical cultures. ${ }^{12}$ Accordingly, we have also observed an increase in both chaperones during $24 \mathrm{~h}$ after OGD in our primary cultures of cortical neurons and glia. Protein levels of both chaperones drop consistently after $48 \mathrm{~h}$, probably due to the massive neuronal death observed after $24 \mathrm{~h}$ of OGD. Regulation of the transcription of these chaperones is 
mediated by the binding of transcription factors to the ERSE sequences present in the promoter. XBP1 and ATF6 are transcription factors related to the UPR that could bind to the ERSE sequences and mediate the upregulation of GPR78 and GPR94. As indicated above, we have observed an increase in the processed form of $x b p 1$. In contrast, we were unable to detect cleaved ATF6 $(50 \mathrm{kDa})$ even in the presence of proteasome inhibitor to avoid the fast degradation of this labile form, but OGD promoted the accumulation of the underglycosylated form of ATF6. This partially glycosylated ATF6 shows a faster rate of constitutive transport to the Golgi resulting in a higher level of ATF6 $(50 \mathrm{kDa})$ in the nucleus. ${ }^{16}$ However, the underglycosylated ATF6 form was only evident $24 \mathrm{~h}$ after OGD and would not explain the induction of the chaperones observed a few hours after OGD. We think that processed $x b p 1$ expression is mediating the induction of GRP74 and GRP94, although we cannot exclude the possibility that ATF4 could also be promoting this upregulation in an ERSE-independent way.

Caspase-12 is an ER-resident caspase that is activated under ER stress conditions and can mediate apoptosis. ${ }^{19}$ This caspase requires cleavage of the prodomain to render the active fragment $\mathrm{p} 20$. It has been described that caspase12 is cleaved after transient focal ischemia ${ }^{7}$ and after OGD in neuronal cortical cultures. ${ }^{12}$ Here, we also report that caspase-12 is cleaved after $\mathrm{HI}$ in neonatal brain and in neuronal-glial cortical cultures. Cleavage was already observed at $6 \mathrm{~h}$ post-OGD, although the p20 fragment was only detected after 12 and $24 \mathrm{~h}$ post-OGD. In contrast with the data obtained in previous 'in vivo' studies, ${ }^{7}$ we did not observe an increase in procaspase-12 levels due to $\mathrm{HI}$ or OGD. It is uncertain which mechanism is mediating caspase-12 cleavage after cerebral ischemia, and whether activation of caspase-12 is always related to UPR or could be activated independently. Several mechanisms for caspase-12 activation have been described. It has been reported that caspase-12 activation is mediated by the IRE 1 transmembrane effector protein through a proximity mechanism that promotes the formation of caspase-12 clusters. The formation of IRE1-TRAF2 (tumor necrosis factor receptor-associated factor 2) complex or the translocation of Bim to the ER could be the triggering signal for the formation of the clusters and caspase-12 activation. $^{21,35}$ Also, a non-proximity driven mechanism for activation of caspase-12 has been also reported as several pieces of evidence suggest that calpains, a calcium-dependent protease, could be responsible for the proteolysis and activation of caspase-12.6,19,36 Accordingly, disruption of calcium homeostasis in the ER, would activate pro-caspase-12 cleavage and the UPR. Our data support a calpain-mediated mechanism for OGD-mediated procaspase-12 cleavage. However, we think that OGD-mediated proteolysis of caspase- 12 by calpains occurs independently of the activation of the UPR as it is NMDA receptor-dependent and ER stress is not triggered in NMDA-mediated neuronal death. ${ }^{37}$ Moreover, our data also indicate that NMDA receptor stimulation is sufficient for calpain-mediated procaspase-12 cleavage in the absence of upregulation of the chaperones GRP78 and GRP94.

In summary, we have provided data for the involvement of IRE1 and PERK in the HI and OGD-mediated UPR. Moreover,

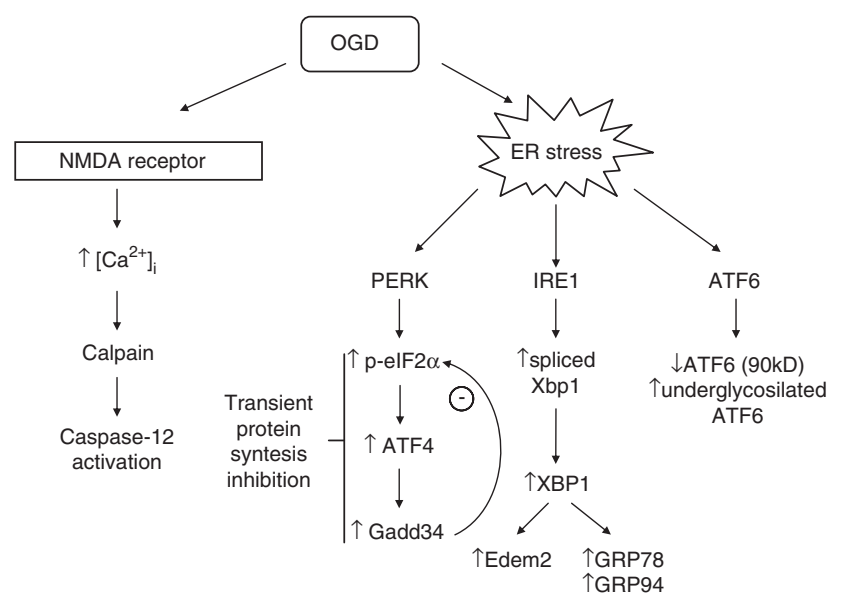

Figure 5 ER stress-activated signal transduction pathways and caspase-12 activation in OGD. OGD activates PERK, which phosphorylates eIF2 $\alpha$ leading to inhibition of protein synthesis, but also increases the translation of ATF4 transcription factor. ATF4 mediate the increase of gadd34 expression, which is involved in the desphophorylation of elF2 $\alpha$. OGD-mediated IRE1 activation allows the processing of $x b p 1 \mathrm{mRNA}$, resulting in enhancement of XBP1 $(54 \mathrm{kDa})$ translation. XBP1 protein binds to ERSE enhancing the expression of grp78 and grp94, and binds to UPRE increasing the edem2 expression. OGD induces an increase of underglycosilated ATF6 form, this increase can be related with the translocation of ATF6 to Golgi to be cleaved. The cleaved ATF6 could translocate to nucleus, but it is not related to the upregulation of grp78 and grp94 expression. OGD activation of NMDAR also causes calcium influx and the subsequent activation of calpain. Calpain proteolyses pro-caspase-12 generating the active form of caspase-12

we conclude that procaspase-12 cleavage is a NMDA receptor and calpain mediated effect, probably independent of ER stress (Figure 5).

\section{Materials and Methods}

Reagents. Fetal calf serum, fetal horse serum and penicillin/streptomycin were obtained from Gibco (Grand Island, NY, USA). Poly-L-lysine (MW <300000), trypsin, soybean trypsin inhibitor, DNAse, Tg, MK-801 and 3-(4,5-dimethylthiazol-2yl)-2,5-diphenyl tetrazolium bromide (MTT) were provided by Sigma-Aldrich (St. Louis, MO, USA). The broad-spectrum caspase inhibitor, ZVAD-FMK, was purchased from Bachem (Heidelberg, Germany). Hoechst 33258 was obtained from Invitrogen (Carlsbad, CA, USA). The calpain inhibitors I, ALLN and brefeldin A (BfA) were from Calbiochem (San Diego, CA, USA). All other chemicals were of the purest grade available from regular commercial sources.

Cell cultures. Primary cultures of mixed rat brain cortical cells containing both neurons and glia were prepared as described by Goldberg MP et al. ${ }^{38}$ and Malagelada $\mathrm{C}$ et al..$^{39}$ with modifications from fetal Wistar rats at 17 days of gestation. The dissociated cells were plated at a density of $3 \times 10^{5}$ cells per square centimeter in basal medium eagle (BME) supplemented with $5 \%$ fetal calf serum, $5 \%$ horse serum, $50 \mathrm{U} / \mathrm{ml}$ penicillin, $50 \mu \mathrm{g} / \mathrm{ml}$ streptomycin, $2 \mathrm{mM}$ glutamine and $10 \mathrm{mM}$ glucose, and plated onto poly-L-lysine pre-coated wells. Cultures were kept at $37{ }^{\circ} \mathrm{C}, 100 \%$ humidity and in a $95 \%$ air $/ 5 \% \mathrm{CO}_{2}$ atmosphere for 7 days in vitro (DIV), when the plating medium was replaced by BME supplemented as above without foetal calf serum and with $10 \%$ horse serum containing $10 \mu \mathrm{M}$ cytosine arabinoside. The experiments were performed at 11-13 DIV. The procedures followed were in accordance with guidelines of the Comissió d'Ėtica en l'Experimentació Animal i Humana of the Universitat Autònoma de Barcelona.

OGD. Cultures were OGD as described before, ${ }^{39}$ with minor modifications. The culture medium was replaced by a glucose-free Earle's balanced salt solution (BSS) with the following composition: $\mathrm{NaCl} 116 \mathrm{mM}, \mathrm{KCl} 5.4 \mathrm{mM}, \mathrm{MgSO}_{4} \cdot 7 \mathrm{H}_{2} \mathrm{O} 0.8 \mathrm{mM}$, $\mathrm{NaH}_{2} \mathrm{PO}_{4} .2 \mathrm{H}_{2} \mathrm{O} 1 \mathrm{mM}, \mathrm{NaHCO}_{3} 26.2 \mathrm{mM}$, Glycine $0.01 \mathrm{mM}, \mathrm{CaCl}_{2} .2 \mathrm{H}_{2} \mathrm{O} 1.8 \mathrm{mM}$, $\mathrm{pH} 7.4$, which was previously equilibrated in $0.8 \% \mathrm{O}_{2} / 94.2 \% \mathrm{~N}_{2} / 5 \% \mathrm{CO}_{2}$ atmosphere 
at $37^{\circ} \mathrm{C}$. The cultures were then placed in humidified hypoxic workstation for 90 min. (Invivo2 400, Ruskinn Technologies, Bridgend, UK) at $37^{\circ} \mathrm{C}$ and $0.8 \% \mathrm{O}_{2}$ $94.2 \% \mathrm{~N}_{2} / 5 \% \mathrm{CO}_{2}$ atmosphere. OGD was terminated by removing the cultures from the hypoxic workstation, replacing the deoxygenated and glucose-free BSS with the pre-OGD culture medium and returning the cells to the normoxic conditions. Control sister culture plates were exposed to oxygenated BSS containing $5.5 \mathrm{~mm}$ glucose in normoxic conditions during the same period of time as the OGD cultures. When used, the calpain or caspase inhibitors (ALLN or ZVAD respectively) were added to culture media 60 min before OGD.

Induction of HI. Unilateral $\mathrm{HI}$ was induced in 7-day-old Wistar rats of both sexes. The pups were anesthetized with halothane $(3.0 \%$ for induction and $1.0-1.5 \%$ for maintenance) in a mixture of nitrous oxide and oxygen, $(1: 1)$, and the duration of anesthesia was $<10 \mathrm{~min}$. The left common carotid artery was cut between double ligatures of prolene sutures (6-0). After the surgical procedure, the wounds were infiltrated with a local anesthetic, and the pups were allowed to recover for $\sim 1 \mathrm{~h}$. The litters were then placed in a chamber perfused with a humidified gas mixture $(7.70 \pm 0.01 \%$ oxygen in nitrogen) for $55 \mathrm{~min}$. The temperature in the gas chamber was kept at $36^{\circ} \mathrm{C}$. Following hypoxic exposure, the pups were returned to their biological dams until killed. Control animals were operated and ligated but not subjected to hypoxia.

The animals were killed by decapitation, and the brains were rapidly dissected out on a bed of ice, weighed, quickly frozen in isopenthane and dry ice and stored at $-80^{\circ} \mathrm{C}$. Cortical tissue rostral to the hippocampus, $\sim 50 \mathrm{mg}$, was dissected out from each hemisphere at $-10^{\circ} \mathrm{C}$. Tissue from the penumbra area was

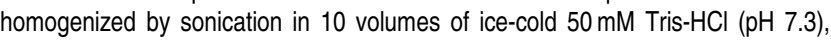
containing $5 \mathrm{mM}$ EDTA, aliquoted and stored at $-80^{\circ} \mathrm{C}$. Homogenate samples were mixed with an equal volume of concentrated (3X) sodium dodecyl sulfate (SDS)-polyacrylamide gel electrophoresis buffer and heated $\left(96^{\circ} \mathrm{C}\right)$ for $5 \mathrm{~min}$. All animal experimentation was approved by the Ethical Committee of Göteborg (approval number 183-99).

Reverse-transcription PCR. Total RNA was obtained using the RNA extraction kit (Qiagen, Hilden, Germany) following the manufacturer's instructions. cDNA was synthesized from $1 \mu \mathrm{g}$ total RNA using SuperScript First-Strand Synthesis System for RT-PCR Kit (Invitrogen, Foster City, CA, USA), following the manufacturer's indications. The reaction was carried out in a thermal cycler as follows: $65^{\circ} \mathrm{C}$ for $5 \mathrm{~min}, 42^{\circ} \mathrm{C}$ for $50 \mathrm{~min}$ and $70^{\circ} \mathrm{C}$ for $15 \mathrm{~min}$. Samples were then kept at $-20^{\circ} \mathrm{C}$ until their usage. The primers used for RT-PCR were: $x b p 1 u$ (F, 5'-AAGGACACGCTTGGGGA-3'; R, 5'-AGAGGCGCACGT-AGTCTG-3'), Xbp1 spliced (F, 5'-TGAGTCCGCAGCAGGT-3'; 5'-AGAGGCGCACGT-AGTCTG-3'); Grp78 (F, 5'-CCACCAGGATGCAGACATTG-3'; R, 5'-AGGGCCTCCACTTCCATAGA-3'); Grp94 (F, 5'-AAGGTCATTGTCACGTCGAAA-3'; 5'-GTGTTTCCTCTTGGGTCA GC-3'); the growth arrest and DNA damage inducible gene 34 (Gadd34) (F, 5' -GTC CATTTCCTTGCTGTCTG-3'; R, 5'-AAGGCGTGT-CCATGCTCTGG-3'); edem2 (F, 5'-GGGAGAGCCGGTCAGATA-3'; 5'-CCCAAACTGCTTCCATACAG-3') and actin (F, 5'-TACAACCTTCTTGCAGCTCC-3'; 5'-GGATCTTCATGAGGTAGTCTG-3'). $P C R$ conditions for semi-quantitative analysis were set up for each pair of primers to obtain non-saturated products. Quantification was estimated by band densitometry on $2 \%$ agarose gels (Gene Tools software; Syngene, Cambridge, UK).

Xbp1 processing analysis. cDNA obtained from cortical cultures was used as templates for PCR amplification. We used $X b p 1$ primers that flank the processed site (F, 5'-AAA-CAGAGTAGCAGCACAGACTG- $3^{\prime}$ and $\mathrm{R}, 5^{\prime}$-GGATCTCTAA-GACT AGAGGCTTGGTG-3'). Pstl (New Engand BioLabs, Ipswich, MA, USA) digestion of the samples was carried out from 30 I of each purified PCR product overnight. ${ }^{28,40}$ Semi-quantification of the processed Xbp1 (Xbp1p) was estimated by band densitometry on $3 \%$ agarose gels of non-saturated PCR products.

Western blot analysis. Cells were homogenized in lysis buffer $(62.5 \mathrm{mM}$ Tris- $\mathrm{HCl}, 2 \%$ SDS, $10 \%$ glycerol, $50 \mathrm{mM}$ DTT and $0.01 \%$ bromophenol blue). Protein concentration was measured by bicinchoninic acid assay (BCA Protein Assay kit; Pierce, Rockford, IL, USA). A measure of $30 \mu \mathrm{g}$ of protein was resolved on a $10 \%$ SDS-PAGE gel $(7.5 \%$ for Gadd 34$)$ and transferred onto Hybond-P (GE Healthcare, Buckinghamshire, UK), polyvinylidene difluoride membranes. The blots were blocked with 5\% dry milk in TBS containing Tween $20(0.1 \%)$ and incubated overnight at $4{ }^{\circ} \mathrm{C}$ in blocking buffer containing primary antibodies. The following primary antibodies and dilutions were used rat anti-GRP94 (1/2000; Stressgen Biotechnologies, Victoria, BC, Canada), mouse anti-GRP78 (1/1000; BD
Biosciences, San Diego, CA, USA), rabbit anti-ATF6 $\alpha$ (1/200, Santa Cruz Biotechnologies, Santa Cruz, CA, USA), rabbit anti-ATF4 (1/500; Santa Cruz Biotechnologies), rabbit anti-phosphorylated alpha subunit of eukaryotic initiation factor 2 (elF2 $\alpha$ ) (1/1000; Cell Signaling Technology, Inc., Beverly, MA, USA), rabbit anti-total elF2 $\alpha$ (1/1000; Cell Signaling Technology) mouse anti-caspase-12 (1/500, Sigma-Aldrich), rabbit anti-gadd34 (1:1000; Santa Cruz Biotechnologies), mouse anti-tubulin (1/10000; Sigma-Aldrich), mouse anti-GAPDH (1/20000; BD Biosciences) and mouse anti-b-actin (1/10000; Sigma-Aldrich). The blots were then incubated with horseradish peroxidase-conjugated secondary antibodies (BD Biosciences) in blocking buffer and developed using the ECL Western Blotting Detection Reagent (GE Healthcare).

Immunocytochemistry. The cells were plated on 24-well culture plates and fixed in $4 \%$ paraformaldehyde in TBS ( $100 \mathrm{mM}$ Tris, $0.9 \%$. $\mathrm{NaCl}, \mathrm{pH} 7.6)$ for $1 \mathrm{~h}$ at $4{ }^{\circ} \mathrm{C}$. After washing, the cells were blocked for $1 \mathrm{~h}$ in TBS-Tween $200.1 \%$ containing $5 \%$ bovine serum albumin (BSA) and then incubated overnight at $4{ }^{\circ} \mathrm{C}$ with the primary antibody against the active form of caspase- 3 (diluted 1:100 in blocking buffer). The cells were washed with TBS-Tween $0.1 \%$ and then incubated with the secondary antibody Alexa fluor 488 (1:500; Invitrogen) in blocking buffer. Cells were analyzed under a non-confocal fluorescent microscope Nikon Eclipse TE2000 (Nikon Instruments Europe, Badhoevedorp, The Netherlands).

Caspase-12 activity. Caspase-12 activity was measured by a fluorometric kit assay according to manufacturer's instructions (BioVision, Mountain Vision, CA, USA). In brief, cells were lysed and the proteins $(150 \mu \mathrm{g})$ were incubated with the caspase-12 substrate ATAD-AFC $(50 \mu \mathrm{M})$ for $1 \mathrm{~h}$ at $37^{\circ} \mathrm{C}$. Samples were transferred to black bottom 96 -wells microplates and were read during $30 \mathrm{~min}$ at $505 \mathrm{~nm}$ in a fluorescence microplate reader (Fluoroskan Ascent; Thermo Labsystems, Waltham, MA, USA). The control reactions were carried out with no protein in the wells and by omitting the substrate. Fluorescence in normoxia was arbitrarily set as 1. Experiments were conducted in triplicate.

Statistical analysis. Statistical significance was determined by one-way analysis of variance followed by Bonferroni's multiple comparison test. A value of $P<0.05$ was accepted as denoting statistical significance.

\section{Conflict of interest}

The authors declare no conflict of interest.

Acknowledgements. This work was supported by grants from Ministerio de Ciencia y Tecnologia (SAF2005-05106 and SAF2008-01904) and by the Red de Investigación Cooperativa Neurovascular to JRA. NB was a recipient of a predoctoral fellowship from the Gobierno Vasco. BB was a recipient of a predoctoral fellowship from the Universitat Autònoma de Barcelona. RF was a recipient of a predoctoral fellowship from the Generalitat de Catalunya. GS is a recipient of a predoctoral fellowship from the MCIN.

1. Hara H, Fink K, Endres M, Friedlander RM, Gagliardini V, Moskowitz MA. Attenuation of transient focal cerebral ischemic injury in transgenic mice expressing a mutant ICE inhibitory protein. J Cereb Blood Flow Metab 1997; 17: 370-375.

2. Malagelada C, XIfrò X, Miñano A, Sabría J, Rodriguez-Alvarez J. Contribution of caspasemediated apoptosis to the cell death caused by oxygen-glucose deprivation in cortical cell cultures. Neurobiol Dis 2005; 20: 27-37.

3. Rao RV, Ellerby HM, Bredesen DE. Coupling endoplasmic reticulum stress to the cell death program. Cell Death Differ 2004; 11: 372-380.

4. Bertolotti A, Zhang Y, Hendershot LM, Harding HP, Ron D. Dynamic interaction of BiP and ER stress transducers in the unfolded-protein response. Nat Cell Biol 2000; 2: 326-332.

5. Shen J, Chen X, Hendershot L, Prywes R. ER stress regulation of ATF6 localization by dissociation of BiP/GRP78 binding and unmasking of Golgi localization signals. Dev Cell 2002; 3: 99-111.

6. Nakagawa T, Zhu H, Morishima N, Li E, Xu J, Yankner BA et al. Caspase-12 mediates endoplasmic-reticulum-specific apoptosis and cytotoxicity by amyloid-beta. Nature 2000; 403: 98-103.

7. Shibata M, Hattori H, Sasaki T, Gotoh J, Hamada J, Fukuuchi Y. Activation of caspase-12 by endoplasmic reticulum stress induced by transient middle cerebral artery occlusion in mice. Neuroscience 2003; 118: 491-499.

8. Obeng EA, Boise LH. Caspase-12 and caspase- 4 are not required for caspase-dependent endoplasmic reticulum stress-induced apoptosis. J Biol Chem 2005; 280: 29578-29587. 
9. Paschen W, Doutheil J. Disturbances of the functioning of endoplasmic reticulum: a key mechanism underlying neuronal cell injury? J Cereb Blood Flow Metab 1999; 19: 1-18.

10. Tajiri S, Oyadomari S, Yano S, Morioka M, Gotoh T, Hamada Jl et al. Ischemia-induced neuronal cell death is mediated by the endoplasmic reticulum stress pathway involving CHOP. Cell Death Differ 2004; 11: 403-415.

11. Hayashi T, Saito A, Okuno S, Ferrand-Drake M, Dodd RL, Chan PH. Damage to the endoplasmic reticulum and activation of apoptotic machinery by oxidative stress in ischemic neurons. J Cereb Blood Flow Metab 2005; 25: 41-53.

12. Chen X, Kintner DB, Luo J, Baba A, Matsuda T, Sun D. Endoplasmic reticulum Ca2+ dysregulation and endoplasmic reticulum stress following in vitro neuronal ischemia: role of $\mathrm{Na}+-\mathrm{K}+-\mathrm{Cl}$ - cotransporter. J Neurochem 2008; 106: 1563-1576.

13. Zhu $C$, Wang $X, X u F$, Bahr BA, Shibata M, Uchiyama $Y$ et al. The influence of age on apoptotic and other mechanisms of cell death after cerebral hypoxia-ischemia. Cell Death Differ 2004; 12: 162-176.

14. Dever TE, Yang W, Astrom S, Bystrom AS, Hinnebusch AG. Modulation of tRNA(iMet) elF-2, and elF-2B expression shows that GCN4 translation is inversely coupled to the level of elF-2.GTP.Met-tRNA(iMet) ternary complexes. Mol Cell Biol 1995; 15: 6351-6363.

15. Novoa I, Zeng H, Harding HP, Ron D. Feedback Inhibition of the Unfolded Protein Response by GADD34-mediated Dephosphorylation of elF2\{alpha\}. J Cell Biol 2001; 153: 1011-1022.

16. Hong M, Luo S, Baumeister P, Huang JM, Gogia RK, Li M et al. Underglycosylation of ATF6 as a novel sensing mechanism for activation of the unfolded protein response. J Biol Chem 2004; 279: 11354-11363.

17. Hong M, Li M, Mao C, Lee AS. Endoplasmic reticulum stress triggers an acute proteasomedependent degradation of ATF6. J Cell Biochem 2004; 92: 723-732.

18. Lee AH, Iwakoshi NN, Glimcher LH. XBP-1 regulates a subset of endoplasmic reticulum Resident chaperone genes in the unfolded protein response. Mol Cell Biol 2003; 23: 7448-7459

19. Nakagawa T, Yuan J. Cross-talk between two cysteine protease families. Activation of caspase-12 by calpain in apoptosis. J Cell Biol 2000; 150: 887-894.

20. Rao RV, Hermel E, Castro-Obregon S, del RG, Ellerby LM, Ellerby HM et al. Coupling endoplasmic reticulum stress to the cell death program. Mechanism of caspase activation. J Biol Chem 2001; 276: 33869-33874.

21. Yoneda T, Imaizumi K, Oono K, Yui D, Gomi F, Katayama T et al. Activation of caspase-12, an endoplastic reticulum (ER) resident caspase, through tumor necrosis factor receptorassociated factor 2-dependent mechanism in response to the ER stress. J Biol Chem 2001; 276: $13935-13940$

22. Blomgren K, Zhu C, Wang X, Karlsson JO, Leverin AL, Bahr BA et al. Synergistic activation of caspase-3 by m-calpain after neonatal hypoxia-ischemia: a mechanism of 'pathological apoptosis'? J Biol Chem 2001; 276: 10191-10198.

23. Harding HP, Zhang $\mathrm{Y}$, Bertolotti $\mathrm{A}$, Zeng $\mathrm{H}$, Ron D. Perk is essential for translationa regulation and cell survival during the unfolded protein response. Mol Cell 2000; 5: 897-904.

24. Althausen S, Mengesdorf T, Mies G, Olah L, Nairn AC, Proud CG et al. Changes in the phosphorylation of initiation factor elF-2alpha, elongation factor eEF-2 and p70 S6 kinase after transient focal cerebral ischaemia in mice. J Neurochem 2001; 78: 779-787.

25. DeGracia DJ, Kumar R, Owen CR, Krause GS, White BC. Molecular pathways of protein synthesis inhibition during brain reperfusion: implications for neuronal survival or death. $J$ Cereb Blood Flow Metab 2002; 22: 127-141.

26. Hayashi T, Saito A, Okuno S, Ferrand-Drake M, Dodd RL, Chan PH. Oxidative injury to the endoplasmic reticulum in mouse brains after transient focal ischemia. Neurobio Dis 2004 15: 229-239.

27. Kumar R, Krause GS, Yoshida H, Mori K, DeGracia DJ. Dysfunction of the unfolded protein response during global brain ischemia and reperfusion. J Cereb Blood Flow Metab 2003 23: 462-471.

28. Paschen W, Aufenberg C, Hotop S, Mengesdorf T. Transient cerebral ischemia activates processing of xbp1 messenger RNA indicative of endoplasmic reticulum stress. J Cereb Blood Flow Metab 2003; 23: 449-461.

29. Morimoto N, Oida Y, Shimazawa M, Miura M, Kudo T, Imaizumi K et al. Involvement of endoplasmic reticulum stress after middle cerebral artery occlusion in mice. Neuroscience 2007; 147: 957-967.

30. Ma Y, Hendershot LM. Delineation of a negative feedback regulatory loop that controls protein translation during endoplasmic reticulum stress. J Biol Chem 2003; 278 34864-34873.

31. Mengesdorf T, Proud CG, Mies G, Paschen W. Mechanisms underlying suppression of protein synthesis induced by transient focal cerebral ischemia in mouse brain. Exp Neurol 2002; 177: 538-546.

32. Neumar RW, DeGracia DJ, Konkoly LL, Khoury JI, White BC, Krause GS. Calpain mediates eukaryotic initiation factor $4 \mathrm{~g}$ degradation during global brain ischemia. $\mathrm{J}$ Cereb Blood Flow Metab 1998; 18: 876-881.

33. Yoshida H, Matsui T, Yamamoto A, Okada T, Mori K. XBP1 mRNA is induced by ATF6 and spliced by IRE1 in response to ER stress to produce a highly active transcription factor. Cell 2001; 107: 881-891.

34. Olivari S, Galli C, Alanen H, Ruddock L, Molinari M. A novel stress-induced EDEM variant regulating endoplasmic reticulum-associated glycoprotein degradation. J Biol Chem 2005; 280: 2424-2428.

35. Morishima N, Nakanishi K, Tsuchiya K, Shibata T, Seiwa E. Translocation of Bim to the endoplasmic reticulum (ER) mediates ER stress signaling for activation of caspase-12 during ER stress-induced apoptosis. J Biol Chem 2004; 279 50375-50381.

36. Tan Y, Dourdin N, Wu C, De VT, Elce JS, Greer PA. Ubiquitous calpains promote caspase-12 and JNK activation during endoplasmic reticulum stress-induced apoptosis. $J$ Biol Che 2006; 281: 16016-16024.

37. Concannon CG, Ward MW, Bonner HP, Kuroki K, Tuffy LP, Bonner CT et al. NMDA receptor-mediated excitotoxic neuronal apoptosis in vitro and in vivo occurs in an ER stress and PUMA independent manner. J Neurochem 2008; 105: 891-903.

38. Goldberg MP, Choi DW. Combined oxygen and glucose deprivation in cortical cell cultured neurons: calcium-dependent and calcium-independent mechanisms of neuronal injury. Neurosci 1993; 13: 3510-3524.

39. Malagelada C, Xifro X, Badiola N, Sabria J, Rodriguez-Alvarez J. Histamine H2-receptor antagonist ranitidine protects against neural death induced by oxygen-glucose deprivation. Stroke 2004; 35: 2396-2401.

40. Penas C, Guzman MS, Verdu E, Fores J, Navarro X, Casas C. Spinal cord injury induces endoplasmic reticulum stress with different cell-type dependent response. J Neurochem 2007; 102: 1242-1255.

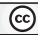

OMEERाEHTS

Cell Death and Disease is an open-access journal published by Nature Publishing Group. This work is licensed under the Creative Commons Attribution-Noncommercial-No Derivative Works 3.0 Unported License. To view a copy of this license, visit http://creativecommons.org/licenses/by-nc-nd/3.0/

\section{Supplementary Information accompanies the paper on Cell Death and Disease website (http://www.nature.com/cddis)}

